\title{
Circulating Leptin, Ghrelin, Glucose, Insulin, C-Peptide, GH, IGF-1, Cor- tisol, and Interleukin-6 Concentrations, and the Systemic Stress Response to Uncomplicated Surgical Injury
}

\author{
Claudio Chiesa*,a,c ${ }^{\text {, John F. Osborn }}{ }^{\mathrm{b}}$, Lucia Pacifico ${ }^{\mathrm{a}, \mathrm{c}}$, Guglielmo Tellan ${ }^{\mathrm{d}}$, Eleonora Poggiogalle ${ }^{\mathrm{c}}$, \\ Roberto Pascone ${ }^{\mathrm{c}}$ and Giovanna Delogu ${ }^{\mathrm{d}}$
}

\author{
${ }^{a}$ Institute of Neurobiology and Molecular Medicine, National Research Council, Rome, Italy; Departments of ${ }^{b}$ Public \\ Health Science; ${ }^{c}$ Pediatrics and ${ }^{d}$ Anesthesia and Intensive Care, "La Sapienza" University of Rome, Viale Regina \\ Elena, 324, 00161-Rome, Italy
}

\begin{abstract}
The mechanisms initiating, regulating and sustaining the systemic stress response to a surgical injury have not all been identified yet. Recent studies point to the adipose tissue as a major endocrine system, the hormones of which influence energy homeostasis, glucose and lipid metabolism, vascular homeostasis, and immune response. Essential elements of this control system are leptin and ghrelin. The purpose of the present study was to compare the patterns of leptin and ghrelin secretion in different perioperative periods in patients undergoing elective cholecystectomy, and to relate the changes in circulating leptin or ghrelin to concomitantly occurring changes in glucose, insulin, C-peptide, growth hormone (GH), insulin-like growth factor (IGF)-1, total cortisol, free cortisol index, and interleukin-6, and other clinical parameters. Thirty patients were included in the study. Blood was sampled at seven time points between one hour prior to the induction of anesthesia (first observation) to approximately 24 hours later. Both leptin and ghrelin displayed a parallel decrease in concentrations from baseline in the intra-and postoperative periods, with a parallel return to baseline on the morning of the first postoperative day. However, at each perioperative period the leptin trend was not associated with that of other substances(including ghrelin).Likewise, the ghrelin time trend was independent of other study variables (including leptin). What triggers this response remains unknown but this study implies that it is unlikely to be the hypothalamicpituitary-adrenocortical, GH/IGF-1, or glucose homeostatic axis, or proinflammatory cytokines.
\end{abstract}

Keywords: Leptin, Ghrelin, Insulin,C-peptide, IGF-1, GH, Cortisol, Interleukin-6, Surgical stress, Systemic stress response.

\section{INTRODUCTION}

To face a great diversity of insults, the body has developed natural defense mechanisms, most of which are accompanied by temporary starvation, without having to rely upon external support. Consequently, the initial response to acute insults, such as illness or trauma, is an increased availability of glucose, amino acids and free fatty acids. Utilization of these substrates is reduced and preferentially directed toward vital organs, such as the brain and the immune system [1]. This acute metabolic response is thought to be at least partly evoked by endocrine changes, including an activated hypothalamic-pituitary-adrenocortical (HPA) axis, hypersecretion of prolactin, growth hormone $(\mathrm{GH})$ in the presence of low circulating insulin-like growth factor (IGF-1), and a low activity state of the thyroid and gonadal axis [2-6]. These changes have been consistently viewed as adaptive or beneficial during the first hours or days of illness, as they may reduce and redirect energy consumption by catabolizing their own stored body fuels, and postpone anabolism [7-9]. The major body fuel becomes fat [10]. In the human, this defense mechanism appears to be fundamental, and is part of the overall "stress response".

*Address correspondence to this author at the Institute of Neurobiology and Molecular Medicine, National Research Council, Rome, Italy; Tel: 3906 4997.9216; Fax: 3906 4997.9215;

E-mail: claudio.chiesa@artov.inmm.cnr.it
This has been studied most commonly in relation to surgery, because the catabolic changes that occur can be observed from a well-defined starting point [11].

Major and moderate surgery represents a physical stress [12]. The systemic stress response to an injury caused by a surgical operation is complex and is followed by a characteristic period of biologic repair with neuroendocrine, acutephase, metabolic, and immunological responses. As such, multiple factors may work in concert to mediate the systemic stress response. Though mechanisms initiating, regulating, and sustaining this response have not all yet been identified [10], the catabolic response to surgical injury is one of the most potent activators of the HPA axis, and alters the GH/IGF-1 axis [12]. During the last years, the role of cytokines in response to surgery, and the interaction between the immunological and neuroendocrine systems, has furthered interest in the subject [9]. Yet, a potentially important insight into the question is provided by recent studies pointing to the adipose tissue as a highly active endocrine organ secreting a range of hormones regulating energy metabolism [13].

The newly discovered secretory function of the adipocytes has shifted the view of the white adipose tissue from a simple energy storage tissue to a major endocrine system, the hormones of which influence energy homeostasis, glucose and lipid metabolism, vascular homeostasis, and immune response [13]. They directly influence other organ systems, 
including the brain, liver, and skeletal muscle, and are significantly regulated by nutritional status [13]. Essential elements of this control system are leptin and ghrelin, both of which signal nutritional status and energy storage levels to the hypothalamic neurons that regulate feeding behavior $[14,15]$. The reciprocal actions of leptin and ghrelin are mediated by the hypothalamic neurons in the arcuate nucleus containing neuropeptide Y (NPY) and agouti-related peptide, which induce feeding, and neurons containing proopiomelanocortin and cocaine and amphetamine-regulated transcript, which inhibit feeding. Leptin inhibits NPY neurons and stimulates proopiomelanocortin neurons to suppress feeding, whereas ghrelin activates NPY neurons and inhibits proopiomelanocortin neurons to promote food intake [14-16].

The protein leptin, an adipocyte-derived hormone, has dual regulation in human physiology. During periods of weight maintenance, when energy intake and energy output are equal, leptin concentrations reflect total body fat mass. However, in conditions of negative (weight-loss programs) and positive (weight-gain programs) energy balances, the changes in leptin concentrations function as a sensor of energy imbalance $[13,17]$. In this setting, leptin is acutely regulated by departures from the normal energy balance, such as fasting. It is of particular importance that the acute downregulation of leptin by fasting operates independently of the available adipose-tissue triglyceride stores, indicating that the total fast is an equal metabolic stress in lean and obese humans [18].

A major step forward in understanding networks regulating energy homeostasis is the discovery of ghrelin. Since 1999 [19], the volume of literature on ghrelin biology is impressive [15]. However, many unanswered questions remain. Identification of the stimuli and pathways regulating ghrelin synthesis and release is fundamental to discovering new approaches to the diagnosis and treatment of different disease entities $[20,21]$, including those related to the overnutrition of obesity and the catabolic response to surgical trauma [13]. Theoretically, ghrelin is a promising candidate for treating catabolic states and enhancing immune function in cachexia $[14,22]$.

In a previous, preliminary study involving a cohort of adult patients undergoing elective cholecystectomy [23], we showed that serum total ghrelin concentrations significantly decreased from baseline during the intraoperative period, as well as over the course of several hours after surgery, returning to baseline levels on the morning of the first postoperative day. However, these observations needed to be extended to the complex network of factors regulating the systemic stress response to surgical injury, and it was with this aim that in the same cohort of study patients we evaluated (1) whether leptin and ghrelin responses to uncomplicated surgical injury are dependent of one another; and (2) whether these responses are mediated by the HPA, GH/ IGF-1, and glucose homeostatic axes, and proinflammatory cytokines. To our knowledge, this is the first report to evaluate jointly perioperative changes in serum leptin, ghrelin, cortisol, free cortisol index , GH, IGF-1, glucose, insulin, C-peptide, and interleukin (IL)-6 concentrations.

\section{MATERIALS AND METHODS}

\section{Patients}

Thirty patients [ 17 females; age range $20-45$ years; body mass index (BMI) between 18 and $25 \mathrm{Kg} / \mathrm{m}^{2}$ ] with ultrasound-proven cholecystolithiasis undergoing elective cholecystectomy via laparoscopy or laparotomy at the Surgical Department at the Hospital Umberto $\mathrm{I}^{\circ}$ of Rome, were recruited to the study [23]. All patients presented a low surgical risk (American Society of Anesthetists' score 1 or 2). To avoid potential confounding, strict selection criteria were applied. Patients with a diagnosis of choledocholitiasis, jaundice, acute cholecystitis, and pancreatitis; those in whom laparoscopic procedure was converted to laparotomy procedure; those with a history of metabolic, endocrine, hepatic, cardiac or renal disease; those who, before surgery, received medication known to interfere with hormonal responses to stress; those with a history of tobacco use or substance abuse; those with BMI greater than $25 \mathrm{Kg} / \mathrm{m}^{2}$; and those younger than 20 years or older than 50 years were not eligible for the study. The study was approved by the Hospital Ethical Committee, and each participant gave informed consent to be included in the study.

Study patients received one of two surgical procedures. One group(twenty patients, of whom 13 were females)underwent laparoscopic cholecystectomy (LC), while open cholecystectomy (OC) was performed on the other group (ten patients, of whom 4 were females). All surgical procedures were scheduled between the morning hours 08.30-09.00, after an overnight fast. Details of the operative procedures for each group have been published elsewhere [23]. There was no patient in whom laparoscopic procedure was converted to open cholecystectomy. There were no significant differences in the mean duration of surgery (time elapsed from the end of the induction of anesthesia until exsufflation or incision closure) between LC (92 min. \pm 36.8 $\mathrm{SD}$; range, $40-190 \mathrm{~min})$ and $\mathrm{OC}(108 \mathrm{~min} . \pm 30.9 \mathrm{SD}$; range, 80-165 min) groups. All patients were operated on a standardized regimen of general anesthesia [23]. As oral and intravenous glucose have been reported by some authors to decrease ghrelin levels [24], fluid replacement was performed with normal saline solution during surgery and throughout the postoperative course until the next morning after surgery (see below) when the $7^{\text {th }}$ blood sample was taken. All patients had an uneventful postoperative clinical course, and were discharged within postoperative day 3 .

\section{Samples and Assays}

Serial blood samples were collected from the indwelling venous cannula of each patient at the following times: at the baseline fasting state, preoperatively (sampling time T1: approximately $60 \mathrm{~min}$ before induction of anesthesia); after induction of anesthesia (T2); at half an hour intraoperatively (T3); at the end of surgery,i.e. at exsufflation or incision closure (T4); in the first 6 (afternoon, T5) and 10 (evening, T6) postoperative hours after the start of surgery; and on the morning (08.00) of the first postoperative day (T7). Serum was obtained from these samples, aliquoted for later duplicate measurements of leptin, ghrelin [23], insulin, C-peptide, IGF-1, GH, total cortisol, cortisol-binding globulin (CBG), and IL-6, and frozen at $-80^{\circ} \mathrm{C}$ until the time of their analyses. Conversely, serum glucose concentrations $(\mathrm{mg} / \mathrm{dL})$ were 
measured by the hospital laboratory, through the glucose oxidase method, soon after samples were collected.

We measured GH levels using an IRMA (CIS Bio International, Schering S.A., Gif-Sur-Yvette Cedex, France; detection limit, $0.02 \mathrm{ng} / \mathrm{mL}$ ). An IRMA (Immunotech, Beckman Coulter, Inc., Marseilles, France) was also used to measure IGF-1 (detection limit, $2 \mathrm{ng} / \mathrm{mL}$ ) and C-peptide (detection limit, $0.015 \mathrm{ng} / \mathrm{mL}$ ). A RIA was used to measure human leptin (DRG Diagnostica, Marburg, Germany; detection limit, $0.5 \mathrm{ng} / \mathrm{mL}$ ), insulin (CIS Bio International, Schering S.A., Gif-Sur-Yvette Cedex, France; detection limit, 2.0 $\mu \mathrm{U} / \mathrm{mL}$ ), and total cortisol (RADIM, Pomezia, RM, Italy; detection limit, $2.48 \mathrm{nmol} / \mathrm{L}$ ). As serum total cortisol is approximately $80 \%$ bound to a specific binding protein such as CBG [25], variation in serum CBG has been shown to significantly affect serum cortisol levels in healthy volunteers [26] as well as in patients with critical illness [27, 28]. Thus, in this study, cortisol was not the only parameter followed to evaluate adrenal function; CBG (DRG Diagnostica; detection limit, $0.25 \mathrm{mg} / \mathrm{L}$ ) was also measured, and therefore adrenal function was also evaluated by the free cortisol index (FCI)[defined as serum total cortisol concentration divided by CBG (nanomoles/milligrams)], as a surrogate for the serum free cortisol $[5,25]$. FCI has been previously reported to correlate well with serum free cortisol, the biologically active component, in healthy volunteers [29] as well as in patients undergoing major elective surgery [30]. An enzymelinked immunosorbent assay, Quantikine (R\&D Systems, Minneapolis, MN, USA), was used to measure serum concentrations of IL- 6 .We chose to measure IL- 6 because research into a number of cytokines has identified the key role of this cytokine as local mediator and as major responsible for the acute-phase response.

\section{Statistical Analysis}

A frequency distribution of the 30 observations of each parameter at each of the 7 time points was constructed and inspected. Given that every frequency distribution was positively skewed, the natural logarithm of each observed value was calculated, and these logarithms were used in all subsequent calculations. In order to investigate how the mean level of each parameter changed between the first and the seventh (and last) observation, two-way analysis of variance (in which the rows represented the patients and the columns were the 7 time points) was applied to the logarithms of each parameter. Differences between values observed at two time points were evaluated using the paired $t$ test on the logarithms of the values. Pearson's product moment correlation with two-tailed probability values was used to measure the strength of association between the variables at any given time point. Multiple regression analysis was used to investigate whether the gender of the patients and the type of operation influenced the mean levels of the logarithms of the laboratory variables. A $p$ value of less than 0.05 was considered to be statistically significant.

\section{RESULTS}

After induction of anesthesia, at T2, geometric mean concentrations of most substances were significantly lower than the baseline (Table 1). However, at this sampling time, geometric mean concentrations of both ghrelin and GH did not decrease significantly compared to baseline, while IL-6 concentrations remained very low. Leptin levels displayed a biphasic pattern similar to that previously reported for ghrelin [23]; during surgery, they still decreased significantly compared to the baseline values, reaching a minimum at both T4 and T5, after which they slightly increased at T6, returning to baseline values at T7 (Table 1). Thus the time trends of leptin as well as of ghrelin appear to be a function of the intra- and postoperative periods considered (Table 1).

With respect to the glucose homeostatic axis, there was no significant change in basal serum insulin and C-peptide levels at any of the defined intra- and postoperative time points. In contrast, serum glucose concentrations increased significantly during surgery, reaching a peak at the end of surgery and then falling toward the starting concentrations before operation (Table 1). There was a slow but progressive and significant decline in circulating IGF-1 concentrations from T4 to T7 (Table 1). Total cortisol concentrations did not change significantly at $\mathrm{T} 3$, peaking at $\mathrm{T} 4$, and decreasing thereafter. In contrast, FCI was significantly higher than the baseline at T3 as well as T4 time points, after which it approached the baseline values at any postoperative period (Table 1). Serum GH concentrations increased significantly during surgery, remained elevated until the end of surgery, and then showed a tendency to return to baseline within the earlier postoperative period (T5). This was followed, however, by a significant increase of serum GH concentrations from baseline over the later postoperative periods (Table 1). IL-6 concentrations were not increased significantly from baseline until 6 hours after the start of surgery. This increase was maintained, with IL-6 values remaining significantly greater than baseline concentrations in later postoperative study periods (Table $\mathbf{1}$ ).

In regression analysis, gender, duration of surgery, and type of surgical procedure had no significant effect on $\log$ ghrelin [23], GH, IGF-1, glucose, insulin, C-peptide, and total cortisol concentrations, and FCI when adjusted for patients and times. In contrast, gender had a significant effect on log leptin concentrations when adjusted for duration and type of surgical procedure, with females having significantly higher $(\mathrm{p}<0.0001)$ levels than males. Conversely, the type of surgical procedure was independently associated with IL-6 response. In fact, serum IL-6 was significantly increased in patients undergoing laparotomy ( $\mathrm{p}<0.0001$ ), which in turn indicated less surgical injury following laparoscopic approach. Nonetheless, serum IL-6 changes showed similar kinetics in both groups (data not shown), peaking in the immediate postoperative period (T5), and remaining increased on the morning of the first postoperative day.

As the time trends of both ghrelin and leptin appeared to be a function of the intra-and postoperative periods considered, multiple regression analysis was used to evaluate, after adjustment for gender and type of surgical procedure, whether at each perioperative period the ghrelin trend was associated with that of other study substances (including leptin), and whether the leptin trend was associated with that of other study variables(including ghrelin). In this regression model, changes in ghrelin as well as in leptin concentrations at each perioperative period were not found to depend on any change in other study variables. 
Table 1. Geometric Mean Values (95 \% CI) of Study Humoral Factors in the Cohort of 30 Patients Undergoing Elective Cholecystectomy at the Sampling Times $\mathrm{T} 1$ to $\mathrm{T} 7$ as Defined in the METHODS

\begin{tabular}{|c|c|c|c|c|c|c|c|}
\hline & \multicolumn{7}{|c|}{ Sampling Times } \\
\hline $\begin{array}{l}\text { Leptin } \\
\mathrm{ng} / \mathrm{mL}\end{array}$ & $\begin{array}{c}5.4 \\
(4.7-6.2)\end{array}$ & $\begin{array}{c}4.6^{\mathrm{a}} \\
(4.0-5.3)\end{array}$ & $\begin{array}{c}4.3^{c} \\
(3.7-4.9)\end{array}$ & $\begin{array}{c}3.7^{\mathrm{c}} \\
(3.2-5.6)\end{array}$ & $\begin{array}{c}3.7^{\mathrm{c}} \\
(3.2-5.6)\end{array}$ & $\begin{array}{c}4.0^{\mathrm{a}} \\
(3.5-4.6)\end{array}$ & $\begin{array}{c}6.6 \\
(5.7-7.6)\end{array}$ \\
\hline $\begin{array}{l}\text { Ghrelin }^{\pi} \\
\mathrm{pg} / \mathrm{mL}\end{array}$ & $\begin{array}{c}231 \\
(197-271)\end{array}$ & $\begin{array}{c}221 \\
(188-258)\end{array}$ & $\begin{array}{c}178^{\mathrm{a}} \\
(152-208)\end{array}$ & $\begin{array}{c}161^{\mathrm{a}} \\
(137-188)\end{array}$ & $\begin{array}{c}142^{\mathrm{c}} \\
(121-166)\end{array}$ & $\begin{array}{c}156^{\mathrm{b}} \\
(133-182)\end{array}$ & $\begin{array}{c}250 \\
(213-293)\end{array}$ \\
\hline $\begin{array}{l}\text { Glucose } \\
\mathrm{mg} / \mathrm{dL}\end{array}$ & $\begin{array}{c}90 \\
(85-95) \\
\end{array}$ & $\begin{array}{c}79^{a} \\
(75-83) \\
\end{array}$ & $\begin{array}{c}96^{\mathrm{a}} \\
(91-101)\end{array}$ & $\begin{array}{c}109^{c} \\
(103-115)\end{array}$ & $\begin{array}{c}93 \\
(88-98)\end{array}$ & $\begin{array}{c}97 \\
(92-102)\end{array}$ & $\begin{array}{c}91 \\
(86-96)\end{array}$ \\
\hline $\begin{array}{l}\text { Insulin } \\
\mu \mathrm{U} / \mathrm{mL}\end{array}$ & $\begin{array}{c}17 \\
(15-20) \\
\end{array}$ & $\begin{array}{c}14^{\mathrm{a}} \\
(12-16) \\
\end{array}$ & $\begin{array}{c}16 \\
(14-19) \\
\end{array}$ & $\begin{array}{c}16 \\
(14-19)\end{array}$ & $\begin{array}{c}15 \\
(13-18)\end{array}$ & $\begin{array}{c}16 \\
(14-19)\end{array}$ & $\begin{array}{c}18 \\
(18-21)\end{array}$ \\
\hline $\begin{array}{c}\mathrm{GH} \\
\mathrm{ng} / \mathrm{mL}\end{array}$ & $\begin{array}{c}0.8 \\
(0.5-1.2) \\
\end{array}$ & $\begin{array}{c}1.0 \\
(0.6-1.5)\end{array}$ & $\begin{array}{c}2.3^{\mathrm{b}} \\
(1.5-3.6) \\
\end{array}$ & $\begin{array}{c}1.7 \\
(1.1-2.6) \\
\end{array}$ & $\begin{array}{c}1.2 \\
(0.8-1.9) \\
\end{array}$ & $\begin{array}{c}2.0^{\mathrm{b}} \\
(1.3-3.1) \\
\end{array}$ & $\begin{array}{c}2.4^{\mathrm{b}} \\
(1.6-3.7) \\
\end{array}$ \\
\hline $\begin{array}{c}\text { Total cortisol } \\
\text { nmol/L }\end{array}$ & $\begin{array}{c}539 \\
(464-626)\end{array}$ & $\begin{array}{c}358^{\mathrm{c}} \\
(281-450)\end{array}$ & $\begin{array}{c}639 \\
(550-750)\end{array}$ & $\begin{array}{c}720^{\mathrm{b}} \\
(639-812)\end{array}$ & $\begin{array}{c}518 \\
(388-699)\end{array}$ & $\begin{array}{c}498 \\
(365-665)\end{array}$ & $\begin{array}{c}403 \\
(296-566)\end{array}$ \\
\hline $\begin{array}{l}\mathrm{CBG} \\
\mathrm{mg} / \mathrm{L}\end{array}$ & $\begin{array}{c}59 \\
(57-61)\end{array}$ & $\begin{array}{c}51^{\mathrm{c}} \\
(49-53)\end{array}$ & $\begin{array}{c}52^{\mathrm{c}} \\
(50-54)\end{array}$ & $\begin{array}{c}52^{\mathrm{c}} \\
(50-54)\end{array}$ & $\begin{array}{c}51^{\mathrm{c}} \\
(49-53)\end{array}$ & $\begin{array}{c}47^{\mathrm{c}} \\
(45-49)\end{array}$ & $\begin{array}{c}49^{c} \\
(47-51)\end{array}$ \\
\hline $\begin{array}{c}\text { FCI } \\
\mathrm{nmol} / \mathrm{mg}\end{array}$ & $\begin{array}{c}9.0 \\
(7.6-10.6)\end{array}$ & $\begin{array}{c}5.2^{\mathrm{b}} \\
(3.5-7.7)\end{array}$ & $\begin{array}{c}12.2^{\mathrm{b}} \\
(10.4-14.3)\end{array}$ & $\begin{array}{c}13.5^{\mathrm{c}} \\
(11.8-15.6)\end{array}$ & $\begin{array}{c}10.0 \\
(7.7-13.3)\end{array}$ & $\begin{array}{c}10.5 \\
(7.7-14.1)\end{array}$ & $\begin{array}{c}8.2 \\
(6.0-11.3)\end{array}$ \\
\hline
\end{tabular}

Compared with T1: ${ }^{\mathrm{a}} \mathrm{p}<0.05 ;{ }^{\mathrm{b}} \mathrm{p}<0.01 ;{ }^{\mathrm{c}} \mathrm{p}<0.0001$.

IIPerioperative ghrelin changes as previously reported [23].

\section{DISCUSSION}

The present study reports on the complex time course and interrelationship of leptin, ghrelin, free cortisol index, glucose homeostatic axis, GH, IGF-1, and cytokines such as IL6 in different perioperative periods of a cohort of adult patients undergoing elective cholecystectomy whose strict selection criteria, similar pre-, intra- and postoperative conditions other than the surgical approach, low surgical risk, and uncomplicated intra- and postoperative clinical course represent the unique feature of this study.

As expected [31], induction of anesthesia was associated with a significant decrease in serum concentrations of most substances compared with baseline. However, no reduction in serum GH concentration was observed. This agrees with data previously reported by other Authors in the same category of patients [31]. Yet, the novel finding of our study is that ghrelin may be added to the list of substances whose concentrations remain stable after induction of anesthesia.

To some extent our findings of a decrease in leptin concentrations from baseline in the intra- and postoperative periods of adult patients undergoing elective cholecystectomy, with a return to baseline on the morning of the first postoperative day, were not unexpected, and complement those of other studies relating leptin to the systemic stress response over the immediate postoperative period. Wallace et al. measured circulating concentrations of leptin in nine patients who underwent an elective mini-laparotomy cholecystectomy [32]. Compared with baseline values, over the $72 \mathrm{~h}$ from the start of surgery, leptin concentrations dramatically dropped at $3 \mathrm{~h}$, peaked at $18 \mathrm{~h}$, and returned to baseline thereafter. Kain et al. studied the leptin response in 21 women who underwent major elective abdominal surgery [33]. In that study, mean leptin concentrations had a maximal decrease to $49 \%$ of baseline $2 \mathrm{~h}$ after surgery, and increased to just above baseline $24 \mathrm{~h}$ postoperatively. ModanMoses et al. studied the leptin response in 29 patients, who were operated for the correction of congenital heart defects by open heart surgery involving conventional cardiopulmonary bypass (CPB) techniques or closed palliative heart surgery [34]. In the twenty patients who underwent CPB, leptin fell during $\mathrm{CPB}$ to $51 \%$ of baseline, then gradually increased, reaching $120 \%$ of baseline levels at $12-18 \mathrm{~h}$ postoperatively. In the nine patients undergoing closed-heart 
surgery, leptin levels displayed a pattern resembling that encountered after CPB.

In view of the above findings, the leptin response observed during surgical stress has been interpreted as an appropriate adaption to an acute stress to help maintain homeostasis [35]. Indeed, adaption to starvation or caloric restriction may be the primary physiologic need for which leptin (as well as ghrelin) evolved as a peripheral regulator of energy balance $[18,36]$. Thus, a role for leptin in preventing obesity might have less evolutionary importance. During mammalian evolution, the threat of starvation far outweighed that of obesity, so there was probably stronger selection for the ability to respond to being underweight than for the ability to respond to being overweight [36].

Most conditions of acute stress are accompanied by starvation or at least a degree of protein malnutrition [37-40]. As with ghrelin [23], falling leptin concentrations may be an appropriate process secondary to a metabolic stress such as nutritional deprivation. In humans, chronic undernutrition (marasmus and kwashiorkor) and acute dietary restriction (fasting) induce a clear-cut reduction of serum IGF-1 associated with increased GH levels [41], suggestive of a nutritionally acquired lack of $\mathrm{GH}$ action or $\mathrm{GH}$ resistance [13]. As such, the neuroendocrine profile observed in the present study was very similar to that generally observed in acute dietary restriction [7]. It included a clear-cut decrease in CBG (a liver-derived plasma protein) (Table 1), and IGF-1, coupled with elevated circulating levels of GH.

Despite their similar biphasic response to acute perioperative stress, a novel finding of this study was the observation that the adaptive responses exhibited by ghrelin and leptin during the well defined surgical injury of cholecystectomy, were independent of one another. These observations raise important questions about the interrelationship between ghrelin and leptin. In plasma, reciprocal relationships exist between ghrelin and leptin [15]. In rats, fasting augments the pulsatile secretion of ghrelin, and diminishes leptin secretion [42]. It was predicted that in the absence of ghrelin, leptin and insulin levels would not be affected by feeding and fasting. However, identical changes in plasma insulin and leptin levels induced by feeding and fasting of wild-type mice were also observed in ghrelin ${ }^{-/}$and $\mathrm{Ghsr}^{-/-}$ mice $[43,44]$. Hence,the secretion of leptin and insulin in response to changes in energy balance is not dependent upon either ghrelin or its receptor. The opposing effects of ghrelin and leptin on appetite are not explained by ghrelin regulation of leptin secretion, but may involve mutual antagonism at the functional level [15].

A component of the response to surgical injury is the neuroendocrine stimulation of the HPA axis. As expected, FCI increased throughout surgery, suggesting a temporal inverse relationship between the marked decreases in leptin or ghrelin concentrations and the marked elevations of FCI throughout surgery. However, we were unable to observe a statistically significant reciprocal association between leptin and FCI at any of the pertinent sample periods. Previous studies [32-34] have shown an inverse relationship between leptin and cortisol, suggesting that an initial cortisol surge triggers an initial decrease in leptin concentrations, and that this increase in cortisol in turn promotes a rise in circulating leptin. A general note must be taken regarding the type and method of data analysis used in these studies. When analyzing data from such studies, it is essential to adjust the associations to exclude the potential confounding effects of age, gender, weight, body mass index, and other factors such as exogenous administration of glucocorticoids, or determination of total cortisol concentrations as the only parameter to evaluate adrenal function. The controversy surrounding the issue is further highlighted by Torpy and colleagues[45], who questioned whether the reported effects of glucorticoids on leptin levels may not be a physiologic phenomenon, but rather a pharmacologic one, occurring only with high doses of synthetic glucorticoids [45].

We also were unable to observe a statistically significant reciprocal association between ghrelin and FCI at any of the pertinent sample periods. We therefore confirm previous reports showing no relation between daily ghrelin and cortisol (either in total amount by area under curve or secretion patterns) [46].

The major fuel source in the normal human is glucose. Leptin regulates glucose homeostasis through the central nervous system , adipose tissue, pancreas, liver, and muscle [47]; ghrelin may antagonize leptin in specific cells present in each of these target organs [15]. A prominent feature of the response to injury is hyperglycemia. Studies in patients undergoing cholecystectomy demonstrate a small increase in hepatic glucose production with markedly decreased peripheral utilization [10]. The linear relationship between blood glucose and insulin levels existing prior to surgery was absent afterwards [10]. A major mediator is epinephrine; infusion into postabsorptive normal subjects results almost immediately in enhanced gluconeogenesis, and reduced peripheral tissue uptake of glucose [48]. Similar but delayed effects are seen with cortisol infusion [49]. Epinephrine inhibits insulin secretion, whereas cortisol does not inhibit insulin release and thus does not result in severe hyperglycemia. Thus it is not surprising that in our clinical setting a prominent feature of the intraoperative response was a significant increase of baseline glucose values which showed no correlation with serum total cortisol concentrations and, more importantly, with FCI. Keeping in mind the above background, the observation of apparently normal insulin concentrations throughout the study period was also not unexpected. This finding was confirmed by the similar pattern of C-peptide. In this study, we chose to measure both insulin and $\mathrm{C}$-peptide because endogenous insulin secretion is assessed best by measurement of C-peptide, which is cosecreted with insulin in a one-to-one molar ratio but unlike insulin experiences little first pass clearance by the liver [50]. As such, in our cohort of patients who underwent elective cholecystectomy and had an uncomplicated clinical course, both insulin and C-peptide remained stable, within reference intervals, through the entire study period. Although supraphysiologic insulin levels can suppress ghrelin levels and, conversely, cause a modest increase in leptin secretion $[13,51]$, in our controlled environment circulating insulin at physiologic levels did not appear to be either leptin or ghrelin regulatory factor candidate. Moreover, in our selective environment we were unable to observe any correlation of glucose with leptin as well as with ghrelin concentrations. Similar observations have been reported by others $[13,15,51$ 53]. 
The systemic stress response is also mediated by inflammatory mediators originating from the surgical wound. Of these mediators IL-6 appears to be the major regulator of this response and,as has been shown previously [54,55], serum levels of IL- 6 are proportional to the severity of tissue. IL-6 has a crucial role in the induction and control of the acutephase protein response. In the present study, serum IL-6 changes showed similar kinetics in both groups (data not shown), peaking in the immediate postoperative period (T5), and remaining increased on the morning of the first postoperative day. The findings were not unexpected [55]. The observation of significantly higher values of IL-6 in the laparotomy group suggests that the acute-phase response after open surgery is more intense than after laparoscopy cholecystectomy, which in turn indicates less surgical injury following laparoscopic approach, whereas a host of other parameters shift to variably similar extents in the two patient subgroups. This is in line with previous observations that the differences in biochemical responses to OC versus LC essentially are limited to acute-phase reactions [56]. Targarona et $a l$. found no differences in concentrations of glucose, insulin, glucagons, GH, serum total cortisol, adrenocorticotropic hormone, and prolactin between patients undergoing cholecystectomy by LC and those by OC [56]. However, the acute-phase response component (including IL-6 changes)was less intense after LC compared to OC [56].

In summary, this study documents that one of the adaptive mechanisms associated with surgical stress is a fall in serum leptin and ghrelin. Some factor triggered during the systemic stress response to surgical injury is responsible for the observed phenomena, although it remains unknown but appears to be neither GH nor cortisol nor glucose homeostatic axis nor the type and severity of surgical procedure.

\section{REFERENCES}

[1] Cahill, G.F. Starvation in man. N. Engl. J. Med., 1970, 12, 668675.

[2] Chrousos, G.P. The hypothalamic-pituitary adrenal axis and immune mediated inflammation. N. Engl. J. Med., 1995, 332, 13511362.

[3] Noel, G.L.; Suh, H.K.; Stone, S.J.G.; Frantz, A.E. Human prolactin and growth hormone release during surgery and other conditions of stress. J. Clin. Endocrinol. Metab., 1972, 35, 840-851.

[4] Ross, R.; Miell, J.; Freeman, E.; Jones, J.; Matthews, D.; Preece, M.; Buchanan, C. Critically ill patients have high basal growth hormone levels with attenuated oscillatory activity associated with low levels of insulin-like growth factor-1. Clin. Endocrinol., 1991, 35, 47-54.

[5] Mesotten, D.; Vanhorebeek, I.; Van den Berghe, G. The altered adrenal axis and treatment with glucocorticoids during critical illness. Nat. Clin. Pract. Endocrinol. Metab., 2008, 4, 496-505.

[6] Luque, R.M.; Park, S.; Kineman, R.D. Severity of the catabolic condition differentially modulates hypothalamic expression of growth hormone-releasing hormone in the fasted mouse: potential role of neuropeptide $\mathrm{Y}$ and corticotrophin-releasing hormone. Endocrinology, 2007, 148, 300-309.

[7] Van den Berghe, G.; de Zegher, F.; Bouillon, R. Acute and prolonged critical illness as different neuroendocrine paradigms. $J$. Clin. Endocrinol. Metab., 1998, 83, 1827-1834.

[8] Van den Berghe, G. The neuroendocrine response to stress is a dynamic process. Best Pract. Res. Clin. Endocrinol. Metab., 2001,15, 405-419.

[9] Desborough, J.P. The stress response to trauma and surgery. Br. J. Anaesth., 2000, 85, 109-117.

[10] Weissman, C. The metabolic response to stress: an overview and update. Anesthesiology, 1990, 73, 308- 327.
[11] Burton, D.; Nicholson, G.; Hall, G. Endocrine and metabolic response to surgery. Contin. Educ. Anaesth. Crit. Care Pain, 2004, 4, 144-147.

[12] Osorio, A.; Vara-Thorbeck, R.; Rosell, J.; Osorio, C.; Ortega, E.; Ruiz-Requena, E. Dehydroepiandrosterone sulfate and growth axis hormones in patients after surgery. World J. Surg., 2002, 26, 10791082.

[13] Meier, U.; Gressner, A.M. Endocrine regulation of energy metabolism: review of pathobiochemical and clinical chemical aspects of leptin, ghrelin, adinopectin, and resistin. Clin. Chem., 2004, 50, 1511-1525.

[14] Wu, J.T.; Kral, J.G. Ghrelin: integrative neuroendocrine peptide in health and disease. Ann. Surg., 2004, 239, 464-474.

[15] Sun,Y.; Asnicar, M.; Smith, R.G. Central and peripheral roles of ghrelin on glucose homeostasis. Neuroendocrinology, 2007, 86, 215-228.

[16] Luque, R.M.; Huang, Z.H.; Shah,B.; Mazzone,T.; Kineman, R.D. Effects of leptin replacement on hypothalamic-pituitary growth hormone axis function and circulating ghrelin levels in $o b / o b$ mice. Am. J. Physiol. Endocrinol. Metab., 2007, 292, E891-E899.

[17] Farooqi, I. S.; O'Rahilly, S. Leptin: a pivotal regulator of human energy homeostasis. Am. J.Clin. Nutr., 2009, 89(Suppl.), 980S984S.

[18] Kolaczynski, J.W.; Considine, R.V.; Ohannesian, J.; Marco, C.; Opentanova, I.; Nyce, M.R.; Myint, M.; Caro, J.F. Responses of leptin to short-term fasting and refeeding in humans: a link with ketogenesis but not ketones themselves. Diabetes, 1996, 45, 15111515.

[19] Kojima, M.; Hosoda, H.; Date, Y.; Nakazato, M.; Matsuo, H.; Kangawa, K. Ghrelin is a growth- hormone-releasing acylated peptide from stomach. Nature, 1999, 402, 656-660.

[20] Hellstrom, P.M. Faces of ghrelin-research for the 21st century. Neurogastroenterol. Motil., 2009, 21, 2-5.

[21] Van del Lely, A.J. Ghrelin and new metabolic frontiers. Horm. Res., 2009, 71(Suppl. 1), 129-133.

[22] DeBoer, M.D. Emergence of ghrelin as a treatment for cachexia syndromes. Nutrition, 2008, 24, 806-814.

[23] Chiesa, C.; Osborn, J.F.; Pacifico, L.; Tellan, G.; Strappini, P.M.; Fazio, R.; Delogu, G. Circulating ghrelin in patients undergoing elective cholecystectomy. Clin. Chem., 2005, 51, 1258-1261.

[24] Shiiya, T.; Nakazato, M.; Minuta, M.; Date, Y.; Mondal, M.S.; Tanaka, M.; Nozoe, S.I.; Hosoda, H.; Kangawa, K.; Matsukura, S. Plasma ghrelin levels in lean and obese humans and the effect of glucose on ghrelin secretion. J. Clin. Endocrinol. Metab., 2002, 87, 240-244.

[25] Bonte, H.A.; van den Hoven, R.J.; van der Sluijs, V.G.; Vermes, I. The use of free cortisol index for laboratory assessment of pituitary-adrenal function. Clin. Chem. Lab. Med., 1999, 37, 127-132.

[26] Dhillo, W.S.; Kong, W.M.; le Roux, C.W.; Alaghband-Zadeh, J.; Jones, J.; Carter, G. ; Mendoza, N.; Meeran, K.; O'Shea, D. Cortisol-binding globulin is important in the interpretation of dynamic tests of the hypothalamic-pituitary-adrenal axis. Eur. J. Endocrinol., 2002, 146, 231-235.

[27] Pugeat, M.; Bonneton, A.; Perrot, D.; Rocle-Nicolas, B.; Lejeune, H.; Grenot, C.; Dechaud, H.; Brebant, C.; Motin, J.; Cuilleron, C.Y. Decreased immunoreactivity and binding activity of corticosteroidbinding globulin in serum in septic shock. Clin. Chem., 1989, 35, 1675-1679.

[28] Hammond, G.L.; Smith, C.L.; Paterson, N.A.; Sibbald, W.J. A role for corticosteroid-binding globulin in delivery of cortisol to activated neutrophils. J. Clin. Endocrinol. Metab., 1990, 71, 34-39.

[29] le Roux, C.W.; Sivakumaran, S.; Alaghband-Zadeh, J.; Dhillo, W.; Kong, W.M.; Wheeler, M.J. Free cortisol index as a surrogate marker for serum free cortisol. Ann. Clin. Biochem., 2002, 39 (Pt4), 406-408.

[30] le Roux, C.W.; Chapman, G.A.; Kong, W.M.; Dhillo, W.S.; Jones, J.; Alaghband-Zadeh, J. Free cortisol index is better than serum total cortisol in determining hypothalamic-pituitary-adrenal status in patients undergoing surgery. J. Clin. Endocrinol. Metab., 2003, 88, 2045-2048

[31] Giesecke, K.; Hamberger, B.; Jarnberg, P.O.; Klingstedt, C.; Persson, B. High- and low-dose fentanyl anaesthesia: hormonal and metabolic responses during cholecystectomy. Br. J.Anaesth., 1988, $61,575-582$. 
[32] Wallace, A.M.; Sattar, N.; McMillan, D.C. The co-ordinated cytokine/hormone response to acute injury incorporates leptin. Cytokine, 2000, 12, 1042-1045.

[33] Kain, Z.N.; Zimolo, Z.; Heninger, G. Leptin and the perioperative neuroendocrinological stress response. J. Clin. Endocrinol. Metab., 1999, 84, 2438-2442.

[34] Modan-Moses, D.; Ehrlich, S.; Kanety, H.; Dagan, O.; Pariente, C.; Esrahi, N.; Lotan,D.; Vishne,T.; Barzilay, Z.; Paret, G. Circulating leptin and the perioperative neuroendocrinological stress response after pediatric cardiac surgery. Crit. Care Med., 2001, 29, 23772382 .

[35] Stryjewski, G.; Dalton, H.J. Circulating leptin: mediator or marker of the neuroendocrinological stress response? Crit. Care Med., 2001, 29, 2397-2398.

[36] Schwartz, M.W.; Seeley, R.J. Neuroendocrine responses to starvation and weight loss. N. Engl. J. Med., 1997, 336, 1802-1811.

[37] Hermansson, M.; Wickelgren, R.B.; Hammarqvist, F.; Bjarnason, R.; Wennstrom, I.; Wernerman, J.; Carlsson, B.; Carlsson, L.M. Measurement of human growth hormone receptor messenger ribonucleic acid by a quantitative polymerase chain reaction-based assay: demonstration of reduced expression after elective surgery. $J$. Clin. Endocrinol. Metab., 1997, 82, 421-428.

[38] Hartman, M.L.; Veldhuis, J.D.; Johnson, M.L.; Lee, M.M.; Alberti, K.G.: Samojlik, E.; Thorner, M.O. Augmented growth hormone (GH) secretory burst frequency and amplitude mediate enhanced GH secretion during a two-day fast in normal men. J. Clin. Endocrinol. Metab., 1992, 74, 757-765.

[39] Thissen, J.P.; Ketelslegers, J.M.; Underwood, L.E. Nutritional regulation of the insulin-like growth factors. Endocr. Rev., 1994, $15,80-101$.

[40] Souba, W.W. Nutritional support. N. Engl. J. Med., 1997, 336, 4148.

[41] Scacchi, M.; Pincelli, A.I.; Cavagnini, F. Nutritional status in the neuroendocrine control of growth hormone secretion: the model of anorexia nervosa. Front. Neuroendocrinol., 2003, 24, 200-224.

[42] Bagnasco, M.; Kalra, P.S.; Kalra, S.P. Ghrelin and leptin pulse discharge in fed and fasted rats. Endocrinology, 2002, 143, 726729.

[43] Sun, Y.; Wang, P.; Zheng, H.; Smith, R.G. Ghrelin stimulation of growth hormone release and appetite is mediated through the growth hormone secretagogue receptor. Proc. Natl. Acad. Sci. USA, 2004, 101, 4679-4684.

[44] Sun,Y.; Ahmed, S.; Smith, R.G. Deletion of ghrelin impairs neither growth nor appetite. Mol. Cell. Biol., 2003, 23, 7973-7981.

[45] Torpy, D.J.; Bornstein, S.R.; Cizza, G.; Chrousos, G.P. The effects of glucocorticoids on leptin levels in humans may be restricted to acute pharmacologic dosing. J. Clin. Endocrinol. Metab., 1998, 83, 1821-1822.
[46] Purnell, J.Q.; Weigle, D.S.; Breen, P.; Cummings, D.E. Ghrelin levels correlate with insulin levels, insulin resistance, and highdensity lipoprotein cholesterol, but not with gender, menopausal status, or cortisol levels in humans. J. Clin. Endocrinol. Metab., 2003, 88, 5747-5752.

[47] Ceddia, R.B.; Koistinen, H.A.; Zierath, J.R.; Sweeney, G. Analysis of paradoxical observations on the association between leptin and insulin resistance. FASEB J., 2002, 16, 1163-1176.

[48] Black, P.R.; Brooks, D.C.; Bessey, P.Q.; Wolfe, R.R.; Wilmore, D.W. Mechanisms of insulin resistance following injury. Ann. Surg., 1982, 196, 420-435.

[49] Rizza, R.A.; Mandarino, L.J.; Gerich, J.E. Cortisol-induced insulin resistance in man: impaired suppression of glucose production and stimulation of glucose utilization due to a postreceptor detect of insulin action. J .Clin. Endocrinol. Metab., 1982, 54, 131-138.

[50] Palmer, J.P.; Fleming, G.A.; Greenbaum, C.J.; Herold, K.C.; Jansa, L.D.; Kolb, H.; Lachin, J.M.; Polonsky, K.S.; Pozzilli, P.; Skyler, J.S.; Steffes, M.W. C-peptide is the appropriate outcome measure for type 1 diabetes clinical trials to preserve beta-cell function: report of an ADA workshop, 21-22 October 2001. Diabetes, 2004, 53, 250-264.

[51] Chan, J.L.; Bullen, J.; Lee, J.H.; Yiannakouris, N.; Mantzoros, C.S. Ghrelin levels are not regulated by recombinant leptin administration and/or three days of fasting in healthy subjects. J. Clin. Endocrinol. Metab., 2004, 89, 335-343.

[52] Flanagan, D.E.; Evans, M.L.; Monsod, T.P.; Rife, F.; Heptulla, R.A.; Tamborlane, W.V.; Sherwin, R.S. The influence of insulin on circulating ghrelin. Am. J. Physiol. Endocrinol. Metab., 2003, 284, E313-E316.

[53] Schaller,G.; Schmidt, A.; Pleiner, J.; Woloszczuk, W.; Wolzt, M.; Luger, A. Plasma ghrelin concentrations are not regulated by glucose or insulin: a double-blind, placebo-controlled crossover clamp study. Diabetes, 2003 , 52, 16-20.

[54] Cruickshank, A.M.; Fraser, W.D.; Burns, H.J.; Van Damme, J. Shenkin, A. Response of serum interleukin-6 in patients undergoing elective surgery of varying severity. Clin. Sci., 1990, 79, 161165.

[55] Karayiannakis, A.J.; Makri, G.G.; Mantzioka, A.; Karousos, D.; Karatzas, G. Systemic stress response after laparoscopic or open cholecystectomy: a randomized trial. Br. J. Surg., 1997, 84, 467471.

[56] Targarona, E.M.; Pons, M.J.; Balague, C.; Espert, J.J.; Moral, A.; Martinez, J.; Gaya, J.; Filella, X.; Rivera, F.; Ballesta, A.; Trías, M. Acute phase is the only significantly reduced component of the injury response after laparoscopic cholecystectomy. World. J. Surg., 1996, 20, 528-553.

(C) Chiesa et al.; Licensee Bentham Open.

This is an open access article licensed under the terms of the Creative Commons Attribution Non-Commercial License (http://creativecommons.org/licenses/by-nc/3.0/) which permits unrestricted, non-commercial use, distribution and reproduction in any medium, provided the work is properly cited. 